\title{
Assessment of topiramate's efficacy and safety in epilepsy
}

Prem P. Gupta, Anup Kumar Thacker', Jamal Haider², Shilpi Dhawan², Neerjesh Pandey², Awanish Kumar Pandey ${ }^{4}$

Department of Pharmacology, All India Institute of Medical Sciences, Patna, Bihar, ${ }^{1}$ Department of Neurology, Dr. Ram Manohar Lohia Institute of Medical Sciences, Lucknow, ${ }^{2}$ Department of Pharmacology, Baba Raghav Das Medical College, ${ }^{4}$ Department of Pharmacy, ITM, Gorakhpur, ${ }^{3}$ Department of Pharmacology, TMC, Teerthanker Mahaveer University, Moradabad, Uttar Pradesh, India

\begin{abstract}
Objective: To study the significance of topiramate (TPM) addition on seizure control in treatment of epilepsy. Design: A prospective open label add-on trial of TPM addition in patients with epilepsy was done. The events of baseline phase of 12 weeks followed by titration and maintenance phases were recorded. Assessment of the number of seizure and emergent adverse effects was done by a monthly visit for each case. Main Outcome Measures: Reduction of more than $50 \%$ mean seizure frequency or response ratio of 0.33 was taken as the criteria for responders. Statistical Analysis: Normal Z-test for significance of differences between two proportions and Chi-square test for presence of association was applied and mean age, median duration, sex ratio, percentage prevalence were depicted. Results: Significant responses to TPM in both partial as well as generalized seizures were observed $(\mathrm{Z}=6.66, P<0.001$ and $\mathrm{Z}=4.185$, $P<0.01)$. The effect was more pronounced in patients with partial seizures. However, the overall response was highly significant $(\mathrm{Z}=7.839, P<0.001)$. The best response was noted at the dose of $200-300 \mathrm{mg} /$ day $(\mathrm{Z}=6.708, P<0.001)$. More than $35 \%$ cases of partial and generalized seizures reported more than $75 \%$ reduction levels. The drug was well tolerated in more than $65 \%$ cases for side effects on psychosis, giddiness, and anorexia. Mild side effects were seen only in about less than $35 \%$ cases. Conclusions: TPM was found as a significantly effective add-on anticonvulsant with some limitation or mild side effects.
\end{abstract}

Key words: Antiepileptic drug, seizures, topiramate

\section{Introduction}

Management and control of epilepsy is still a challenge. Recently, surgical remedial measures for lesions opened a new era in the management of these patients. ${ }^{[1-3]}$ However, paucity of comprehensive epilepsy care centers having facilities of epilepsy surgery limit its scope for majority of such patients, particularly in poorly developed areas. Therefore a search of newer antiepileptic drugs (AEDs) to control epilepsy continues. Topiramate (TPM) is one such compound with a known therapeutic potential in these patients. It is a novel sulphamate substituted monosaccharide ${ }^{[4]}$ with multiple mechanisms of action

\begin{tabular}{|c|l|}
\hline \multicolumn{2}{|c|}{ Access this article online } \\
\hline Quick Response Code: & Website: \\
\hline & www.ruralneuropractice.com \\
\cline { 2 - 2 } & \\
\hline & DOI: \\
\hline
\end{tabular}

contributing to its efficacy in several seizure types. So the efficacy and safety of TPM as add-on therapy is being extensively investigated in various types of clinical trials at several places.

Electrophysiological and biochemical studies on neurons have identified several properties of TPM contributing to its anticonvulsant effect. These include reduction of the frequency of action potential generation following subjection of hippocampal neurons to a sustained depolarization that produced repetitive neuronal firing; ${ }^{[5]}$ potentiation of some gamma-aminobutyrate (GABA)-activated receptors (benzodiazipine insensitive receptors). ${ }^{[6]}$ TPM is rapidly absorbed from the gastrointestinal tract and its absorption is unaffected by food. In addition, TPM inhibits some isoenzymes of carbonic anhydrase, although this pharmacological effect is thought to be a minor component of its antiepileptic activity. ${ }^{[7,8]}$ Double-blind placebo-controlled trials had shown that TPM was consistently effective as an adjunctive therapy

Address for correspondence:

Dr. Prem P. Gupta, Department of Pharmacology, All India Institute of Medical Sciences (AIIMS), Patna, Bihar, India. E-mail: drprempgupta@ gmail.com 
in adults with partial onset seizures with or without secondary generalization. ${ }^{[9,10]}$ The kinetics of other antiepileptic medication was generally not affected by concomitant TPM therapy. Addition of topiramate at doses of $100-800 \mathrm{mg} /$ day produced no clinically significant changes in the plasma concentration of carbamazepine, valproate, phenobarbitone, or primidone. ${ }^{[11-14]}$

\section{Materials and Methods}

To assess the safety and efficacy of TPM in patients of partial and generalized tonic-clonic seizures had been carried out in the departments of pharmacology and neurology of B.R.D Medical College, Gorakhpur. The diagnosis of the epilepsy was established on the basis of clinical history and electroencephalographic examination (EEG). All the seizures were classified according to the classification of seizures laid down by International League Against Epilepsy (ILAE, 1981). ${ }^{[15]}$ Each epilepsy was classified according to syndromic classification projected ILAE (ILAE, 1989). ${ }^{[16]}$ A total of 106 consenting patients attending Neurology out-patient department (OPD) whose age was beyond 2 years formed the study subjects. Patients with a treatable cause of seizures (e.g. a metabolic disturbance, toxic exposure, or an active infection) or Pseudoseizures and those with progressive neurological disorders who have hepatic, renal, and cardiac diseases and/or breast feeding and pregnant were excluded from the study.

\section{Study design}

Study consisted of two phases. In the first phase, that is, Baseline phase: Which consisted of 12 weeks, during which patients continued to take their AEDs. Patients were observed for the frequency of seizures, duration, and type of seizures during this phase. The second phase, that is, Treatment Phase: Which can be divided in two phases (a) Titration phase (b) Maintenance phase.

\section{Titration phase}

The initial dose of TPM was $50 \mathrm{mg} /$ day $(1 \mathrm{mg} / \mathrm{kg})$ with fortnightly increments of $50 \mathrm{mg}$ until the maximum effective or maximum tolerated dose was reached. The total tolerated dose was not allowed to exceed $500 \mathrm{mg}$. It was administered in twice a day regimen.

\section{Maintenance phase}

The maximum effective/tolerated dose reached during titration phase was allowed to continue for at least 6 months. Concomitant AEDs were reduced if seizure control was complete and TPM as monotherapy was tried.

\section{Data collection and analysis}

At each study visit, the monthly seizure counts based on a review of patient diaries and treatment emergent adverse events, including intercurrent illness and injury reported by the patients and dosages of TPM and concomitant AEDs were recorded. EEG and biochemical tests for hepatorenal functions were done as and when required.

\section{Efficacy assessment and statistical analysis}

Patients were classified basically in two groups, as responders and nonresponders. The classification was based on $\geq 50 \%$ reduction in the baseline mean seizures frequency in a month or those with a response ratio of 0.33 or less. Response ratio is the difference between seizures frequency in the treatment $(T)$ and baseline periods $(B)$ divided by their sum $(T-B / T+B)$. Negative values indicate fewer seizures.

The percentage difference among the responders and the nonresponders group as a whole and as per the type of seizures was evaluated for statistical significance by calculating Normal Z-test.

\section{Results}

A total of 106 patients were studied of which 70 were males and 36 were females. Of these, $40.56 \%$ patients were having epilepsy for less than 5 years and the maximum number $53.77 \%$ cases were having it from 5 to 20 years duration. Median duration of epilepsy was 7.6 years [Table 1].

The mean age of the patients was $21.45 \pm 10.24$ years. Age-wise distribution is given in Table 2. A highly significant difference was observed between prevalence of cases $17.92 \%$ above and $82.07 \%$ below 20 years of age $(Z=9.345 P<0.001)$.

Complex partial seizures were the commonest $52.83 \%$, while $38.7 \%$ had generalized tonic-clonic seizures, $4.71 \%$ had simple partial seizures and $3.77 \%$ had

Table 1: Duration-wise prevalence of epilepsy

\begin{tabular}{lcc}
\hline \multirow{2}{*}{$\begin{array}{l}\text { Duration of } \\
\text { epilepsy (years) }\end{array}$} & \multicolumn{2}{c}{ Patients } \\
\cline { 2 - 3 }$<5$ & No & $\%$ \\
\hline $5-20$ & 57 & 40.56 \\
$>20$ & 6 & 53.77 \\
Total no of patients & 106 & 5.66 \\
Median duration of epilepsy & 6 years & \\
Sex & & \\
M & 70 & Male female ratio \\
& & $1.94: 1$ \\
\hline
\end{tabular}


absence seizures. Median baseline seizure frequency per month for partial seizure was 10 seizures per month and 6.5 seizures per month for generalized tonic-clonic seizures. The baseline characteristics of patients are summarized in Table 3.

Of the total patients enrolled, $7.55 \%$ patients were on one concomitant AED 54.71\% patients were on two AEDs, while $37.73 \%$ patients were on more than two AEDs. The computed tomography (CT) scan was done in $69.81 \%$ cases and EEG tests in all cases, but it showed insignificant differences between proportions of normal and abnormal findings [Table 4].

During the study period, 10 cases dropped out from the trial for different reasons, and in 8 cases, drug was withdrawn due to adverse effects, thus $88(83.0 \%)$ patients completed the trial. Of all cases, $79.55 \%$ responded well to the treatment and $20.45 \%$ were nonresponders. The most highly significant response $(82.69 \%)$ was from cases with partial seizures $(Z=6.65 P<0.001)$ followed by significant response $(75.75 \%)$ from generalized seizures $(Z=4.185, P<0.05)$, but insignifant where seizures were absent [Table 5].

\section{Efficacy}

Out of the 106 patients, 88 patients entered the maintenance phase of these; $79.55 \%$ patients were found to be responders. The responder rate was $82.69 \%$ for partial seizures, $75.75 \%$ for generalized seizures, and $66.66 \%$ for absence seizures [Table 5]. The difference between responders and nonresponders was highly significant statistically in group as a whole and in patients with partial seizures and generalized seizures. The difference was most highly significant in patients with partial seizures, however, it was not statistically significant in patients with absence seizures.

Percentage reduction in monthly seizure rate is summarized in Table 6 . Among the 52 patients having partial seizures who entered the treatment phase responders were $82.69 \%$ [Table 5]; of these, $46.15 \%$ patients had shown reduction in seizure frequency between $50 \%$ and $75 \%$ and $19.23 \%$ patients showed $75-99 \%$ reduction, while $17.30 \%$ patients became totally seizure free. Out of 25 responders having generalized seizures [Table 5], 39.39\% patients had shown $50-75 \%$ reduction in seizure frequency, $24.24 \%$ patients showed $75-99 \%$ reduction in seizure frequency, while $12.2 \%$ patients became totally seizure free.

The minimum effective dose of TPM was $100 \mathrm{mg} /$ day [Table 7] represent the response by maximal TPM dosages of 100, 200, 300, and $400 \mathrm{mg} /$ day, respectively. Best response to TPM therapy in
Table 2: Age-wise prevalence of epilepsy

\begin{tabular}{lccccc}
\hline $\begin{array}{l}\text { Age } \\
\text { (years) }\end{array}$ & $\begin{array}{c}\text { Patients } \\
\text { no }(\%)\end{array}$ & $\begin{array}{c}\text { Age at onset } \\
\text { of seizure }\end{array}$ & $\begin{array}{c}\text { Patients } \\
\text { no }(\%)\end{array}$ & \multicolumn{2}{c}{ Test } \\
\hline $2-10$ & $14(13.20)$ & $<20$ years & $87(82.07)$ & 9.34 .5 & $<0.001$ \\
$11-20$ & $43(40.56)$ & & & & \\
$21-40$ & $44(41.50)$ & & & & \\
$41-50$ & $05(4.71)$ & & & & \\
& & $>20$ years & $19(17.92)$ & & \\
Total & $106(100)$ & Total & $106(100)$ & & \\
\hline
\end{tabular}

Table 3: Seizures type incidences

\begin{tabular}{lcc}
\hline Type of seizures & \multicolumn{2}{c}{ Patients } \\
\cline { 2 - 3 } & No & \multicolumn{2}{c}{4.71} \\
\hline Simple partial & 5 & 52.83 \\
Complex partial & 56 & 38.67 \\
Generalized tonic-clonic & 41 & 3.77 \\
Absence seizure & 4 & 100.00 \\
Total & 106 & \multicolumn{2}{c}{ Seizures per month } \\
Median seizure frequency & \multicolumn{2}{c}{6.5} \\
Generalized seizures & \multicolumn{2}{c}{10} \\
Partial seizures
\end{tabular}

Table 4: Clinical assessment of study cases

\begin{tabular}{lcccc}
\hline Test finding & \multicolumn{4}{c}{ No of patients } \\
\cline { 2 - 5 } & No & $\%$ & $\mathbf{Z}$ & $\boldsymbol{P}$ \\
\hline CT scan & & & & \\
$\quad$ Normal & 34 & 32.07 & 0.986 & $>0.05$ \\
$\quad$ Abnormal & 40 & 37.73 & & \\
$\quad$ Total & 74 & 690.81 & & \\
EEG & & & & \\
$\quad$ Normal & 50 & 47.16 & 0.824 & $>0.05$ \\
Abnormal & 56 & 52.83 & & \\
$\quad$ Total & 106 & 100.00 & & \\
Concomitant AEDs & & & & \\
1 & 8 & & 7.55 & \\
2 & 58 & & 54.71 & \\
$>2$ & 40 & & 37.73 & \\
Total & 106 & 100.00 & \\
AEDs - Antiepileptic drugs, CT - Computed tomography, & \\
EEG - Electroencephalographic examination &
\end{tabular}

Table 5: Number of patients with effective response

\begin{tabular}{lcccc}
\hline Response & \multicolumn{4}{c}{ No (\%) } \\
\cline { 2 - 5 } & Partial seizure & Generalized & Absence & Total \\
\hline Responders & $43(82.69)$ & $25(75.75)$ & $2(66.66)$ & $70(79.55)$ \\
Nonresponders & $9(17.30)$ & $8(24.25)$ & $1(33.33)$ & $18(20.45)$ \\
Total & $52(100)$ & $33(100)$ & $3(100)$ & $88(100)$ \\
$Z$ Test & 6.66 & 4.185 & 0.816 & 7.839 \\
$P$ & $<0.001$ & $<0.01$ & $>0.05$ & $<0.001$ \\
\hline
\end{tabular}

terms of percentage responders was noted with TPM dose of $200 \mathrm{mg} /$ day. The difference in number of responders with a dose of $200 \mathrm{mg} /$ day was most highly significant $(Z=6.708, P<0.001)$ followed by significant responses of $100 \mathrm{and} 300 \mathrm{mg} /$ day but the dose of $400 \mathrm{mg} /$ day was not significant statistically $(Z=1.154, P>0.05)$. 


\section{Safety}

The most common adverse effects reported were central nervous system (CNS), related in $36.5 \%$ patients in the form of Anorexia. The next important adverse effects were giddiness, found in $16.7 \%$, asthenia and loss of weight in $12.5 \%$ each, headache in $11.5 \%$ cases, anxiety and insomnia and paresthesia in $8.3 \%$ each, followed by infrequent psychomotor slowing, body ache, vomiting, tremors, diarrhea, which were found in only $2-6 \%$. However, behavioral abnormalities were observed in at most $10.4 \%$ cases. The list of adverse effects is serially summarized in Table 8.

\section{Discussion}

For ethical reasons, the randomized controlled trials, which

Table 6: Levels of reductions in monthly seizure rates

\begin{tabular}{lcccc}
\hline $\begin{array}{l}\text { Reduction } \\
\text { level \% }\end{array}$ & \multicolumn{4}{c}{ No (\%) } \\
\cline { 2 - 5 } & $\begin{array}{c}\text { Partial } \\
\text { seizure }\end{array}$ & Generalized & $\begin{array}{c}\text { Absence } \\
\text { seizures }\end{array}$ & Total \\
\hline 100 & $9(17.30)$ & $4(12.12)$ & - & $13(14.77)$ \\
$75-99$ & $10(19.23)$ & $8(24.24)$ & - & $18(20.45)$ \\
$50-74$ & $24(46.15)$ & $13(39.39)$ & $2(66.66)$ & $39(44.32)$ \\
$0-49$ & $9(17.30)$ & $8(24.24)$ & $1(33.33)$ & $18(20.45)$ \\
Total & $52(100)$ & $33(100)$ & $3(100)$ & $88(100)$ \\
\hline
\end{tabular}

Chi-square at 4 d.f. $=2.378974, P>0.05$

Table 7: Doses of topiramate in relation to responders

\begin{tabular}{lccccc}
\hline Topiramate & \multicolumn{5}{c}{$\boldsymbol{N}(\%)$} \\
\cline { 2 - 6 } dosage & $\mathbf{1 0 0} \mathbf{~ m g}$ & $\mathbf{2 0 0} \mathbf{~ m g}$ & $\mathbf{3 0 0} \mathbf{~ m g}$ & $\mathbf{4 0 0} \mathbf{~} \mathbf{g}$ & Total \\
\hline Responders & $11(68.8)$ & $35(87.5)$ & $12(85.7)$ & $4(66.7)$ & $62(71.26)$ \\
Nonresponders & $5(31.2)$ & $5(12.5)$ & $3(14.3)$ & $2(33.3)$ & $15(17.24)$ \\
Total & $16(100)$ & $40(100)$ & $15(100)$ & $6(100)$ & $87(100)$ \\
$Z$ test & 2.121 & 6.708 & 3.286 & 1.154 & 7.173 \\
$P$ & $<0.05$ & $<0.001$ & $<0.05$ & $>0.05$ & $<0.001$ \\
\hline
\end{tabular}

Table 8: Incidences of most common adverse effects

\begin{tabular}{lccc}
\hline Adverse effects & \multicolumn{2}{c}{ No. of patients } & Total no (\%) \\
\cline { 2 - 3 } & Male & Female & \\
\hline Anorexia & 17 & 18 & $35(36.5)$ \\
Giddiness & 10 & 6 & $16(16.7)$ \\
Asthenia & 6 & 6 & $12(12.5)$ \\
Loss of weight & 6 & 6 & $12(12.5)$ \\
Headache & 6 & 5 & $11(11.5)$ \\
Anxiety and insomnia & 4 & 4 & $8(8.3)$ \\
Paresthesia & 4 & 4 & $8(8.3)$ \\
Psychomotor slowing & 3 & 3 & $6(6.3)$ \\
Body ache & 2 & 2 & $4(4.2)$ \\
Vomiting & 3 & 1 & $4(4.16)$ \\
Tremors & 2 & 1 & $3(3.1)$ \\
Diarrhea & 1 & 1 & $2(2.1)$ \\
Behavioral problems & 7 & 3 & $10(10.4)$ \\
Total & 71 & 62 & $133^{*}$ \\
\hline${ }^{*}$ Include single and multiple symptoms & &
\end{tabular}

are the gold standard for demonstrating clinical ability of any drug, are difficult to conduct in patients with epilepsy, because it is not possible to maximize patient response fully. In such clinical trials of new AEDs, we can typically use a surrogate marker of $50 \%$ reduction in seizure frequency as primary end point. The present prospective open label study was intended to study the efficacy of TPM as add-on therapy and to recognize its adverse effects in patients with difficult to control seizures. Our results clearly show that TPM has significant effect in controlling seizures of all types. The effect being more pronounced in patients with partial seizures [Table 5]. The results have been similar in various open label and double-blind controlled trials. ${ }^{[17-21]}$ The therapeutic effect of TPM in our study was consistent regardless of age, gender, and baseline seizure rate.

Indian trial ${ }^{[22]}$ endorse the efficacy of TPM in patients with partial seizures not controlled with other antiepileptics (such as phenytoin, carbamazepine, valproate, phenobarbitone, gabapentin, etc.). In our study, 88 out of 106 patients were either on one or more AED, but were still suffering from seizures. Out of these patients who entered the maintenance phase, $17.30 \%$ with partial seizures and $12.12 \%$ patients with generalized seizures became completely seizure free [Table 6] and as many as $82.69 \%$ patients with partial seizures, $75.75 \%$ with generalized and $66.6 \%$ patients with absence seizure responded positively [Table 5]. These findings have been corroborated by other studies as well ${ }^{[19-23]}$ [Table 1].

Reife et al. ${ }^{[23]}$ in his pooled analysis of TPM did not record any patient characteristic that would have predicted a diminished or heightened response to TPM. The TPM was found to be equally effective in reducing the frequency of simple partial, complex partial, and secondarily generalized tonic-clonic seizures. The therapeutic effect was found to be consistent regardless of age, gender, and baseline seizure rate. No particular combination of TPM and another AED was found to be more efficacious or better tolerated. Our study endorses this experience as they contained patients of both sexes and the youngest patient was 5 years old. TPM has led to a substantial seizure reduction irrespective of baseline seizure frequency and type.

There are indications that TPM has the potential for use as a monotherapy in controlling seizures. Therefore an attempt can be made to discontinue concomitant AEDs therapy once the seizures are controlled. In reports from two study centers, 41 of the total 129 patients (32\%) were converted to TPM monotherapy. ${ }^{[24,25]}$ These patients included 26 patients $(63 \%)$ who were seizure free for at least 3 months and 7 patients who were 
experiencing simple partial seizure. We could achieve monotherapy in four of our patients who had simple partial seizures. Concomitant withdrawal of other AEDs was achieved in majority of our patients, that is, 1 drug in 41 patients (46.6\%), 2 drugs in 18 patients $(20.45 \%)$, and 3 drugs in 4 patients (4.54\%). In our study, the dosage of TPM varied from 50 to $500 \mathrm{mg} /$ day but the maximum response to TPM was seen at the dosage of $200 \mathrm{mg} /$ day at which $87.5 \%$ and $300 \mathrm{mg} /$ day at which $85.7 \%$ patients responded positively [Table 7]. The difference in responders with different dosages reached statistical significance too. A pooled analysis of TPM, ${ }^{[26]}$ which has suggested $200 \mathrm{mg}$ of TPM as a good target dose for add-on therapy in most patients with an excellent balance between efficacy and tolerability has been confirmed in our study too. However, randomized controlled trials ${ }^{[27,28]}$ have demonstrated that patients tolerability and retention on TPM therapy was improved when TPM was titrated with starting dosages of $50 \mathrm{mg} /$ day without delaying the onset of the therapeutic effect. In our study, we have started the TPM dosage at $50 \mathrm{mg} /$ day with fortnightly increments until the maximum effective or tolerated dosages were achieved.

\section{Conclusion}

To conclude, TPM has been shown as a generally effective and well tolerated add-on therapy in the control of seizures of all types, especially partial seizures. The optimum antiepileptic response is seen at a dose of $200 \mathrm{mg} /$ day with an evident need to titrate the dose according to each patient. The study shows that the efficacy and safety profile of the drug in the population studied is similar to that seen elsewhere.

\section{References}

1. Luders HO, Engel J Jr, Munari C. General principles. In: Engel J Jr, editor. Surgical Treatment of the Epilepsies. $2^{\text {nd }}$ ed. New York: Raven Press; 1993. p. 137-53.

2. Weiser HG, Quesney LF, Morrris H. III. Foramen ovale and peg electrodes. In: Engel J Jr, editor. Surgical Treatment of the Epilepsies. $2^{\text {nd }}$ ed. New York: Raven Press; 1993. p. 331-9.

3. Engel J Jr. Surgery for seizures. N Engl J Med 1996;334:647-52.

4. Marynoff BE, Margul BL. Topiramate. Drugs Future 1989;14:342-4.

5. Coulter DA, Sombati S, De Lorenzo RJ. Selective effects of topiramate on sustained repetitive firing and spontaneous bursting in cultured hippocampal neurons. Epilepsia 1993;34 Suppl 2:123.

6. Brown SD, Wolf HH, Swinyard EA, Twyman RE, White HS. The novel anti-convulsant topiramate enhances GABA-mediated chloride flux. Epilepsia 1993;34 Suppl 2:122-3.

7. Ben-Menachem E, Heriksen O, Dam M. Double blind placebo-controlled trials of topiramate as add-on therapy in patients with refractory partial seizures. Epilepsia 1996;37:539-43.
8. Tassinari CA, Michelluci R, Chauvel P, Chodkiewicz J, Shorvon S, Henriksen $\mathrm{O}$, et al. Double-blind, placebo-controlled trial of topiramate (600 mg daily) for the treatment of refractory partial epilepsy. Epilepsia 1996;37:763-8.

9. Priverta M. Long-term efficacy and safety of topiramate. Epilepsia 1995;36 Suppl 3:S152.

10. Ben-Menachem E. Long-term follow up of patients treated with topiramate for partial seizures. Epilepsia 1995;36 Suppl 3:S152.

11. Johannessen SL. Pharmacokinetics and interaction profile of topiramate: Review and comparison with other new antiepileptic drugs. Epilepsia 1997;38 Suppl 1:S18-23.

12. Sachdeo RC, Sachdeo SK, Walker SA, Kramer LD, Nayak RK, Doose Dr. Steady-state pharmacokinetics of topiramate and carbamazepine in patients with epilepsy during monotherapy and concomitant therapy. Epilepsia 1996;37:774-80.

13. Gisdon LG, Curtin CR, Kramer LD. The steady state (SS) pharmacokinetics (PK) of phenytoin (Dilantin) and topiramate (Topomax) in epileptic patients on monotherapy and during combination therapy. Epilepsia 1994;35 Suppl 8:54.

14. Levy RH, Bishop F, Streeter AJ. Explanation and prediction of drug interactions with topiramate using a CYP450 inhibition spectrum. Epilepsia 1995;36 Suppl 4:47.

15. Proposal for revised clinical and electroencephalographic classification of epileptic seizures. From the Commission on Classification and Terminology of the International League against Epilepsy. Epilpepsia 1981;22:489-501.

16. Proposal for revised classification of epilepsies and epileptic syndromes. Commission on classification and terminology of the international league against epilepsy. Epilepsia 1989;30:389-99.

17. Swinscow TD. Percentage and paired alternatives. In: Statistics at Square One. Plymonth, U.K.: British Medical Association Latimer Trend and Company Ltd; 1987. p. 28-32.

18. Topiramate in medically intractable partial epilepsies: Double-blind placebo-controlled randomized parallel group trial. Korean Topiramate Study Group. Epilepsia 1999;40:1767-74.

19. Montouris GD, Biton V, Rosenfeld WE. Nonfocal generalized tonic-clonic seizures: Response during long-term topiramate treatment. Topiramate YTC/YTCE Study group. Epilepsia 2000;41 Suppl 1:S77-81.

20. Abou-Khalil B. Topiramate in the long-term management of refractory epilepsy. Topiramate YOL Study Group. Epilepsia 2000;41 Suppl 1:S72-6.

21. Gubermann A, Neto W, Gassman-Mayer C; EPAJ-119 Study Group. Low-dose topiramate in adults with treatment- resistant partial-onset seizures. Acta Neurol Scand 2002;106:183-9.

22. Gupta M, Rehman N, Bansal J, Mogre V. Topiramate: A new safe and effective antiepileptic. J Indian Med Assoc 2001;99:449-50.

23. Reife R, Pledger G, Wu SC. Topiramate as add-on therapy: Pooled analysis of randomized controlled trials in adults. Epilepsia 2000;41 Supp 1:S66-71.

24. Rosenfeld WE, Sachdeo RC. Topiramate can be as successful monotherapy. Epilepsia 1995;36 Suppl 4:56.

25. Sachdeo RC, Reife RA, Lim P, Pledger G. Topiramate monotherapy for partial onset seizures. Epilepsia 1997;38:294-300.

26. Peeters K, Adriaenssen I, Wapenaar R, Neto W, Pledger G. A pooled analysis of adjunctive topiramate in refractory partial epilepsy. Acta Neurol Scand 2003;108:9-15.

27. Edwards KR, Kamin M. The beneficial effect of slowing the initial titration rate of topiramate. Neurology 1997;48 Suppl 2:A39.

28. Sackellares JC, Kamin M; Topiramate TPS-TR Study Group. Onset of anticonvulsant effect of topiramate, a new antiepileptic drug. Neurology 1997;48:A37.28

How to cite this article: Gupta PP, Thacker AK, Haider J, Dhawan S, Pandey N, Pandey AK. Assessment of topiramate's efficacy and safety in epilepsy. J Neurosci Rural Pract 2014;5:144-8.

Source of Support: Nil. Conflict of Interest: None declared. 